\title{
Impact of data from recent clinical trials on strategies for treating patients with type 2 diabetes mellitus
}

This article was published in the following Dove Press journal:

Vascular Health and Risk Management

30 December 2009

Number of times this article has been viewed

\section{Pasquale J Palumbo' \\ Jonathan MWert ${ }^{2}$}

'Department of Endocrinology, Mayo Clinic College of Medicine, Scottsdale, AZ, USA; ${ }^{2}$ BlueSpark Healthcare Communications, Basking Ridge, NJ, USA
Correspondence: Pasquale J Palumbo 13400 East Shea Boulevard, Scottsdale, AZ, USA 85259

Tel + I 4803017379

Fax $+\mid 4803017569$

Email palumbo.pasquale@mayo.edu
Abstract: Type 2 diabetes is associated with increased risk for the development of cardiovascular disease (CVD) secondary to hyperglycemia's toxicity to blood vessels. The escalating incidence of CVD among patients with type 2 diabetes has prompted research into how lowering glycated hemoglobin $\left(\mathrm{HbA}_{1 \mathrm{c}}\right)$ may improve CVD-related morbidity and mortality. Data from recent studies have shown that some patients with type 2 diabetes actually have increased mortality after achieving the lowest possible $\mathrm{HbA}_{1 \mathrm{c}}$ using intensive antidiabetes treatment. Multiple factors, such as baseline $\mathrm{HbA}_{1 \mathrm{c}}$, duration of diabetes, pancreatic $\beta$-cell decline, presence of overweight/ obesity, and the pharmacologic durability of antidiabetes medications influence diabetes treatment plans and therapeutic results. Hypertension and dyslipidemia are common comorbidities in patients with type 2 diabetes, which impact the risk of CVD independently of glycemic control. Consideration of all of these risk factors provides the best option for reducing morbidity and mortality in patients with type 2 diabetes. Based on the results of recent trials, the appropriate use of current antidiabetes therapies can optimize glycemic control, but use of intensive glucoselowering therapy will need to be tailored to individual patient needs and risks.

Keywords: type 2 diabetes, diabetes treatment, incretin-based therapies, glucose control, $\mathrm{HbA}_{1 \mathrm{c}}$, cardiovascular disease

\section{Introduction}

Diabetes mellitus affects nearly 25 million people in the United States, with more than $90 \%$ diagnosed with type 2 diabetes. ${ }^{1}$ Individuals with type 2 diabetes are at risk for a multitude of metabolic abnormalities that lead to microvascular and macrovascular complications, with cardiovascular disease (CVD) being the leading cause of mortality in these patients. ${ }^{2}$ Despite advances in the diagnosis and treatment of CVD, mortality has increased in patients with type 2 diabetes at the same time as it has decreased in the general population. ${ }^{3}$

Because of this alarming trend in patients with type 2 diabetes, reducing $\mathrm{CV}$ risk factors, including overweight/obesity, elevated blood pressure (BP), and dyslipidemia, is just as important as reducing hyperglycemia for maximizing outcomes in this patient population. ${ }^{2,4-8}$ The importance of addressing these issues through individualized patient treatment strategies has been confirmed in a number of recent, large-scale clinical trials involving patients with type 2 diabetes. ${ }^{9-13}$

This paper will review data from recently conducted, large-scale clinical trials that evaluated the relationship between duration of disease, extent of glucose lowering, and cardiometabolic risk/CVD outcomes, and the treatment effects of more recently approved antidiabetes agents. The implications of these data on changes in current type 2 diabetes treatment practices will also be reviewed. submit your manuscript | www.dovepress.com

Dovepress 


\section{Optimum intensity of glycemic therapy in type $\mathbf{2}$ diabetes}

Although epidemiologic studies indicate an association between elevated glycated hemoglobin $\left(\mathrm{HbA}_{1 \mathrm{c}}\right)$ and CVD in patients with type 2 diabetes, the effects of intensive glucose lowering on vascular outcomes remain unclear. Large-scale clinical trials enrolling patients with type 2 diabetes, including the Action to Control Cardiovascular Risk in Diabetes (ACCORD) study, ${ }^{9}$ the Action in Diabetes and Vascular Disease: Preterax and Diamicron MR Controlled Evaluation (ADVANCE),${ }^{10}$ and the Veterans Administration Diabetes Trial (VADT) ${ }_{1}^{11}$ were designed to determine whether intensive antidiabetes therapy could reduce CVD events in this patient population. These studies are summarized in Table 1.

The results from these randomized clinical trials showed improved glycemic control (as measured by $\mathrm{HbA}_{1 \mathrm{c}}$ ) with a significant difference demonstrated between the intensive antidiabetes therapy and the standard therapy groups. Blood pressure and serum lipid levels improved with appropriate administration of antihypertensive and dyslipidemia treatments with the antidiabetes therapies. While weight gain was noted in ACCORD and VADT in the intensive antidiabetes therapy group compared with the standard therapy group, there was weight loss in both treatment groups in ADVANCE, with the greater loss occurring in the standard therapy group $(-1 \mathrm{~kg})$ versus the intensive therapy group $(-0.1 \mathrm{~kg})$. Further, ACCORD and ADVANCE were secondary prevention trials for CVD in patients with type 2 diabetes and CVD and/or high risk for CVD, while the VADT study was a primary prevention trial for CVD in veterans with type 2 diabetes.

Data from ACCORD, ADVANCE, and VADT showed that reduction of CVD risk factors in patients with type 2 diabetes is not entirely dependent on the extent of glucose lowering. Instead, other factors, including disease duration and the presence of CVD comorbidities, have an influence on the morbidity and mortality of patients in this population. Intensive therapy in ACCORD was discontinued after a mean 3.5-year follow-up because of increased mortality in this treatment group. ${ }^{9}$

\section{Disease duration, comorbidities, and treatment outcomes in type 2 diabetes}

\section{Vascular complications and disease duration}

Studies such as the Diabetes Control and Complications Trial (DCCT), the Wisconsin Epidemiologic Study of Diabetic Retinopathy (WESDR), and the United Kingdom Prospective
Diabetes Study (UKPDS) have investigated the influence of disease duration and concomitant comorbidities on treatment outcomes.

The DCCT evaluated whether intensive antidiabetes treatment could decrease the frequency and severity of microvascular complications in patients with type 1 diabetes. Data showed that lowering $\mathrm{HbA}_{1 \mathrm{c}}$ was associated with a reduced relative risk of microvascular complications, with the greatest reductions in patients with $\mathrm{HbA}_{1 \mathrm{c}}>9 \% .{ }^{14}$ These findings are also important to patients with type 2 diabetes, as the pathophysiologic mechanisms driving disease progression are similar in type 1 and type 2 diabetes. There was no significant difference in macrovascular complications (CVD or mortality) between the standard and intensive therapy groups. However, a majority (93\%) of the DCCT participants were subsequently followed from 1993-2005 for a mean follow-up of 17 years through the Epidemiology of Diabetes Interventions and Complications (EDIC) study. ${ }^{15}$ This study concluded that intensive diabetes therapy was independently associated with a significant decrease in the risk of CVD after the DCCT even though there was no significant difference in the $\mathrm{HbA}_{1 \mathrm{c}}$ between the treatment groups in subsequent follow-up.

The WESDR examined the 25-year cumulative incidence and duration of macular edema (ME) (a commonly encountered microvascular complication in patients with type 1 and type 2 diabetes), and its association with various CVD risk factors, including hyperglycemia and BP. Data showed that elevated $\mathrm{HbA}_{1 \mathrm{c}}$ and systolic $\mathrm{BP}$ were associated with an increased incidence of diabetic ME $(P<0.004$ for both) in patients with type 1 and type 2 diabetes. ${ }^{16}$ As the duration of diabetes increased, the cumulative incidence of clinically significant ME and all-cause mortality also increased. ${ }^{16}$ Adjustment of data by patient age and gender showed that clinically significant ME was associated with increased CVD mortality in patients diagnosed with diabetes when they were aged $\geq 30$ years. ${ }^{17}$ These data suggest that disease duration and the number of diabetes- and CVD-related comorbidities increase the morbidity and mortality of patients with type 2 diabetes. ${ }^{18}$

Data from other clinical studies have shown that progression of type 2 diabetes and its related risk factors are favorably influenced by early initiation of treatment. In the UKPDS, newly diagnosed patients with type 2 diabetes (median baseline $\mathrm{HbA}_{1 \mathrm{c}} 7.9 \%$ to $8.9 \%$ ) were randomized to receive conventional glucose control (diet) or intensive glucose control (sulfonylurea [SFU], insulin, or metformin [MET] $).{ }^{19}$ Microvascular risk was reduced between 25\% 
Table I Summary of recent CVD outcome trials in patients with type 2 diabetes ${ }^{9-11,13}$

\begin{tabular}{|c|c|c|c|}
\hline & ACCORD & ADVANCE & VADT \\
\hline \multicolumn{4}{|l|}{ Baseline patient characteristics } \\
\hline $\mathrm{N}$ & $|0,25|$ & $\mathrm{II}, \mathrm{I} 40$ & $179 \mid$ \\
\hline Age, mean, $y$ & 62 & 66 & 60 \\
\hline Duration of type 2 diabetes, $y$ & 10.0 & 8.0 & 11.5 \\
\hline Patients with CVD history, \% & 35 & 32 & 40 \\
\hline $\mathrm{BMI}, \mathrm{kg} / \mathrm{m}^{2}$ & 32 & 28 & 31 \\
\hline $\mathrm{HbA}_{I \mathrm{c}}$, median, \% & 8.1 & 7.2 & 9.4 \\
\hline \multicolumn{4}{|l|}{ Protocol characteristics } \\
\hline $\begin{array}{l}\text { Target } \mathrm{HbA}_{\mathrm{Ic}}, \% \\
\text { (intensive vs standard care) }\end{array}$ & $<6$ vs $7-7.9$ & $\begin{array}{l}\leq 6.5 \text { vs usual } \\
\text { (ie, based on local guidelines) }\end{array}$ & $\begin{array}{l}<6 \text { (action if }>6.5 \text { ) vs } \\
\text { planned separation of } 1.5\end{array}$ \\
\hline \multicolumn{4}{|l|}{ On-study characteristics } \\
\hline Follow-up, y & $\sim 3.5$ (mean) & 5.0 (median) & 5.6 (median) \\
\hline $\begin{array}{l}\text { Median } \mathrm{HbA}_{\mathrm{Ic}} \text { achieved, } \% \\
\text { (intensive vs standard care) }\end{array}$ & $6.4 \%$ vs $7.5 \%$ & $6.3 \%$ vs $7.0 \%$ & $6.9 \%$ vs $8.4 \%$ \\
\hline $\begin{array}{l}\text { Patients receiving statin therapy, \% } \\
\text { (from baseline to study end) }\end{array}$ & $\begin{array}{l}\text { Intensive: } 62 \rightarrow 88 \\
\text { Standard care: } 62 \rightarrow 88\end{array}$ & $\begin{array}{l}\text { Intensive: } 28 \rightarrow 46 \\
\text { Standard care: } 29 \rightarrow 48\end{array}$ & 84 (at study end) $^{\mathrm{a}}$ \\
\hline $\begin{array}{l}\text { Patients receiving antiplatelet therapy, \% } \\
\text { (from baseline to study end) }\end{array}$ & $\begin{array}{l}\text { Intensive: } 55 \rightarrow 76 \\
\text { Standard care: } 54 \rightarrow 76\end{array}$ & $\begin{array}{l}\text { Intensive: } 49 \rightarrow 64 \\
\text { Standard care: } 48 \rightarrow 61\end{array}$ & 92 (at study end) $^{\mathrm{a}}$ \\
\hline $\begin{array}{l}\text { Patients receiving antihypertensive therapy, \% } \\
\text { (from baseline to study end) }\end{array}$ & $\begin{array}{l}\text { Intensive: } 85 \rightarrow 91 \\
\text { Standard care: } 86 \rightarrow 92\end{array}$ & $\begin{array}{l}\text { Intensive: } 75 \rightarrow 89 \\
\text { Standard care: } 75 \rightarrow 88\end{array}$ & 72 (at baseline) $^{\mathrm{a}}$ \\
\hline
\end{tabular}

Notes: an VADT no baseline data was provided for statin or antiplatelet use. The use of statin therapy was $86 \%$ in intensively treated and $83 \%$ in standard-treated patients at study end. The use of antiplatelet therapy was $94 \%$ in intensively treated and $91 \%$ in standard-treated patients at study end. $72 \%$ of patients in VADT had hypertension by study definition at baseline. No data for hypertension/hypertensive therapy at study end was reported.

Abbreviations: ACCORD, Action to Control Cardiovascular Risk in Diabetes; ADVANCE, Action in Diabetes and Vascular Disease; Preterax and Diamicron MR Controlled Evaluation; BMI, body mass index; CVD, cardiovascular disease; VADT, Veterans Affairs Diabetes Trial.

to $29 \%$ in the intensive control group compared with the conventional control group during the intervention phase of the study and remained diminished throughout the 10-year post-trial phase despite a convergence of $\mathrm{HbA}_{1 \mathrm{c}}$ in the two treatment groups. ${ }^{19}$ Moreover, although not significant during the interventional phase of the trial, patients in the SFU-insulin group experienced statistically and clinically relevant post-trial reductions in the risk for myocardial infarction $(\mathrm{MI})(15 \%, P=0.01)$ and all-cause mortality $(13 \%, P=0.007){ }^{19}$

Patients with hypertension in the UKPDS were also randomized to stringent (angiotensin-converting enzyme inhibitor or $\beta$-blocker) or less-rigid BP control regimens (without these medications). ${ }^{20}$ During a 6- to 10 -year interventional phase, mean BP was significantly lowered from baseline (146/81 mm Hg) to $143 / 79 \mathrm{~mm} \mathrm{Hg}$ in the intensive control group compared with a slight increase to $152 / 82 \mathrm{~mm} \mathrm{Hg}$, in the less-rigidly controlled group $(P<0.001$ between treatment groups). ${ }^{20}$ These improvements in BP were associated with reduced risk of MI and microvascular disease. ${ }^{20}$
Unfortunately, the differences in CVD risk reduction between the two treatment groups were not sustained once the interventional trial ended. ${ }^{20}$ These data suggest that while early initiation of treating hyperglycemia and vascular complications/comorbidities is associated with improved morbidity and mortality in patients with type 2 diabetes, risk factor controls must be maintained to sustain long-term beneficial outcomes.

\section{Other comorbidities and type 2 diabetes}

A number of studies (Look AHEAD [Action for Health in Diabetes] trial, Framingham Heart study, Diabetes Mellitus Insulin Glucose Infusion in Acute Myocardial Infarction [DIGAMI] studies, the Bypass Angioplasty Revascularization Investigation 2 Diabetes [BARI 2D] trial) have evaluated the impact of comorbidities, such as overweight/obesity and pre-existing CVD, on the morbidity and mortality of patients with type 2 diabetes.

In Look AHEAD, 5145 patients with a body mass index (BMI) $>25 \mathrm{~kg} / \mathrm{m}^{2}$ were treated with either intensive lifestyle 
intervention (ILI) involving increased physical activity and caloric restriction, or diabetes support and education (DSE) requiring attendance at support meetings. ${ }^{21}$ At the end of one year, ILI was associated with clinically significant weight loss, improved diabetes control, reduced CVD risk factors, and a reduction in the use of glucose-lowering medication compared with DSE. ${ }^{21} \mathrm{HbA}_{1 \mathrm{c}}$ decreased from $7.3 \%$ to $6.6 \%$ in the ILI group and from $7.3 \%$ to $7.2 \%$ in the DSE group $(P<0.001)$. High density lipoprotein-cholesterol (HDL-C) increased from baseline ( $44 \mathrm{mg} / \mathrm{dL})$ in both groups after one year, but was significantly more improved in the ILI group $(47 \mathrm{mg} / \mathrm{dL})$ compared with the DSE group (45 mg/dL, $P<0.001) .{ }^{21}$

CVD is frequently present in overweight/obese patients with type 2 diabetes. Individuals with and without obesity and diabetes from the original and offspring cohorts of the Framingham Heart study were assessed for their lifetime risk of CVD. ${ }^{22}$ Over a 30-year period, the lifetime risk of CVD among normal-weight and obese females with diabetes was $54.8 \%$ and $78.8 \%$, respectively. ${ }^{22}$ Among normal-weight and obese males with diabetes, the lifetime risk of CVD was $78.6 \%$ and $86.9 \%$, respectively. ${ }^{22}$ These data showed that the lifetime risk of CVD is higher in patients with type 1 or type 2 diabetes and is further accentuated with increasing adiposity.

The DIGAMI 1 study established that initial intensive metabolic control with intravenous insulin followed by longterm subcutaneous insulin improved clinical outcomes in patients with type 2 diabetes and a prior MI. ${ }^{23}$ The DIGAMI 2 study was conducted to determine whether improvement was due to initial insulin-glucose infusion or to long-term subcutaneous insulin treatment. ${ }^{23}$ DIGAMI 2 compared three specific glucose-lowering regimens in patients with type 2 diabetes or elevated blood glucose and a suspected acute MI upon hospital admission: 1) a 24-hour insulin-glucose infusion followed by long-term subcutaneous insulin; 2) the same initial infusion treatment followed by standard glucose control; and 3) standard glucose control without the initial infusion treatment. ${ }^{24}$ Data demonstrated that although hypoglycemic events occurred most often in the first 24 hours after insulin treatment $(\mathrm{N}=111 ; 12 \%)$ compared with standard glucose control, hypoglycemia during time of admission was not associated with adverse CV outcomes. ${ }^{25}$ Only body weight (odds ratio [OR], 0.97; 95\% confidence interval [CI]: 0.95 to $0.98 ; P<0.0001)$ and diabetes duration $(\mathrm{OR}, 1.03 ; 95 \%$ CI: 1.01 to $1.05 ; P=0.0085)$ were individually predictive of hypoglycemia and future morbidity and mortality. ${ }^{25}$

Upon discharge, patients enrolled in DIGAMI 2 were administered various antidiabetes agents, including insulin,
MET, and SFUs for a median of 2.1 years. The results from post-hoc analyses demonstrated that insulin had a greater risk (updated, adjusted hazard ratio [HR], 1.73; 95\% CI: 1.26 to 2.37; $P=0.0007$ ) than MET (HR, $0.63 ; 95 \% \mathrm{CI}: 0.42$ to 0.95 ; $P=0.03$ ) and SFU (HR, $0.81 ; 95 \%$ CI: 0.57 to $1.14 ; P=0.23$ ) for causing nonfatal $\mathrm{MI}$ and stroke in patients with type 2 diabetes. ${ }^{24}$ Additionally, further subanalysis of DIGAMI 2 data showed that insulin treatment after MI was associated with significantly increased weight gain $(+2.3 \mathrm{~kg}$; 95\% CI: 1.5 to 3.2) and a 2.5-times greater incidence of reinfarction. ${ }^{26}$

Similarly, the BARI 2D trial evaluated whether revascularization and intensive antidiabetes therapy with either insulin-sensitization or insulin-provision could improve $\mathrm{CV}$ outcomes when compared with intensive medical therapy alone in patients with type 2 diabetes and stable coronary artery disease. ${ }^{27}$ After five years of treatment, survival rates did not differ significantly between revascularization $(88.3 \%)$ and medical therapy (87.8\%) groups or between the insulin sensitization (88.2\%) and insulin provision (87.9\%) groups. There was also no significant difference in reduction of $\mathrm{CV}$ events between the revascularization group (77.2\%) and medical treatment group $(75.9 \%)$ or between the insulin sensitization group (77.7\%) and insulin provision group $(75.4 \%) .{ }^{28}$ The results from these trials suggest that multiple factors beyond pre-existing conditions, including disease and comorbidity duration and intensity of selected therapy, interact to affect clinical outcomes in patients with type 2 diabetes.

\section{Multifactorial intervention}

Data from clinical studies have shown that treatment with multiple drug combinations can lower the risk of nonfatal CVD in some patients with type 2 diabetes. Steno- 2 was conducted to evaluate the impact of this approach on $\mathrm{CV}$ risk factors and any-cause and CV-related mortality. Patients $(\mathrm{N}=160)$ with type 2 diabetes and persistent microalbuminuria were treated with either intensive multifactorial intervention (stringent glycemic regulation, treatment with lipid- and BP-lowering agents, and aspirin) or conventional therapy for a mean of 7.8 years and followed-up for a mean of 5.5 years. ${ }^{12}$ Intensive multifactorial intervention resulted in significantly lower $\mathrm{HbA}_{1 \mathrm{c}}$ compared with conventional therapy $(7.9 \%$ vs $9.0 \% ; P<0.01)$, but these differences were no longer significant at the end of follow-up (7.7\% vs 8.0\%). ${ }^{12}$ After intervention, mean BP was reduced significantly with intensive $(131 / 73 \mathrm{~mm} \mathrm{Hg})$ therapy compared with conventional $(146 / 78 \mathrm{~mm} \mathrm{Hg})$ therapy, from $146 / 85 \mathrm{~mm} \mathrm{Hg}$ and $149 / 86 \mathrm{~mm} \mathrm{Hg}$, respectively $(P<0.01$ between treatment groups); significance was not maintained 
during the follow-up period. Fasting serum cholesterol was also significantly reduced with intensive $(159 \mathrm{mg} / \mathrm{dL})$ therapy compared with conventional $(216 \mathrm{mg} / \mathrm{dL})$ therapy, from $210 \mathrm{mg} / \mathrm{dL}$ and $233 \mathrm{mg} / \mathrm{dL}$, respectively $(P<0.01$ between treatment groups); again, significant improvements were not maintained after follow-up. ${ }^{12}$

Steno-2 data also showed that intensive multifactorial therapy was associated with sustained and beneficial effects on vascular complications, and any-cause, and CVD-related mortality. Nine patients in the intensive therapy group died from CVD-related causes compared with 19 in the conventional therapy group $(P=0.03) .{ }^{12}$ Diabetic nephropathy, progression of diabetic retinopathy, and autonomic neuropathy were significantly improved in the intensive therapy group compared with the conventional therapy group over the 13.3 years of observation $\left(P<0.01\right.$ for all). ${ }^{12}$ Although these data indicate that multifactorial care for patients with type 2 diabetes lowers CVD risk factors, morbidity, and mortality, the prompt and intensive implementation of antidiabetes treatments remains a formidable challenge in this patient population.

\section{Treatment strategies for type 2 diabetes}

Guidelines for the treatment of type 2 diabetes have been developed by various professional societies, including the American Association of Clinical Endocrinologists (AACE) and the American Diabetes Association (ADA). The guidelines, which are summarized in Table 2, provide target goals for several factors including glucose, BP, and lipids. ${ }^{2,5}$ Clinicians are encouraged to consider the individual patient needs and to encourage lifestyle changes. Results from clinical studies indicate that these targets are generally reasonable and obtainable but should be individualized and tailored to the needs and abilities of the patient with type 2 diabetes. Adjustments may be necessary for patients aged 65 years or older with and without comorbidities and for other individuals with mental and physical health challenges in order to avoid the potential hazards associated with tight glycemic control.

A list of selected antidiabetes pharmacotherapies with their advantages and disadvantages are presented in Table 3. Many of the available medications, including insulin, SFUs, thiazolidinediones (TZDs), and glinides, are associated with weight gain. ${ }^{8} \mathrm{MET}, \alpha$-glucosidase inhibitors, and dipeptidyl peptidase-IV (DPP-IV) inhibitors are considered weightneutral, ${ }^{8}$ while the glucagon-like peptide-1 (GLP-1) receptor agonists, amylin, and amylin analogs, are associated with weight loss. ${ }^{8}$ Insulin therapy may be useful in the undernourished patient to improve nutritional status and weight while avoiding hypoglycemia. Several reviews discuss the mechanisms of action and impact of these medications on other CVD comorbidities. , $^{8,29,30}$

The ADA and the European Association for the Study of Diabetes has developed a consensus algorithm to help guide initiation and adjustment of diabetes therapy using these agents (Figure 1). ${ }^{8}$ In addition to lifestyle improvements, this algorithm recognizes that clinicians have several antidiabetes medications available to help achieve glycemic targets. MET, SFU, and insulin are considered tier 1 core therapies, while tier 2 therapies include pioglitazone and a GLP-1 receptor agonist. ${ }^{8}$ Rosiglitazone is not recommended for use, and DPP-IV inhibitors are not listed. If tier 1 medications do not offer optimal benefits/glucose lowering, the use of additional agents, such as pioglitazone or a GLP-1 receptor agonist from tier 2, may be considered to provide glycemic

Table 2 Comparison of guidelines for the management of patients with type 2 diabetes

\begin{tabular}{lll}
\hline Target treatment goals & AACE/ACE (2007) & ADA (2009) \\
\hline $\mathrm{HbA}_{\mathrm{Ic}}$ & $\leq 6.5 \%$ & $<7 \%$ \\
Fasting glucose & Fasting plasma glucose $<110 \mathrm{mg} / \mathrm{dL}$ & $\begin{array}{l}\text { Preprandial capillary plasma } \\
\text { glucose, } 70-130 \mathrm{mg} / \mathrm{dL}\end{array}$ \\
Postprandial glucose & 2 -hr postprandial glucose $<140 \mathrm{mg} / \mathrm{dL}$ & $\begin{array}{l}\text { Peak postprandial capillary } \\
\text { plasma glucose }<180 \mathrm{mg} / \mathrm{dL}\end{array}$ \\
BP & & $<130 / 80 \mathrm{~mm} \mathrm{Hg}$ \\
Lipids & $<130 / 80 \mathrm{~mm} \mathrm{Hg}$ & $\mathrm{LDL}-\mathrm{C}<100 \mathrm{mg} / \mathrm{dL}$ \\
& LDL-C $<100 \mathrm{mg} / \mathrm{dL}(<70 \mathrm{mg} / \mathrm{dL}$ for patients & $\mathrm{HDL}-\mathrm{C}>50 \mathrm{mg} / \mathrm{dL}$ \\
& with diabetes and coronary artery disease $)$ & Triglycerides $<150 \mathrm{mg} / \mathrm{dL}$ \\
\hline
\end{tabular}

Notes: an individuals with overt CVD, a lower LDL-C goal of $<70 \mathrm{mg} / \mathrm{dL}$ ( $1.8 \mathrm{mmol} / \mathrm{L})$, using high doses of a statin, is an option.

Abbreviations: AACE, American Association of Clinical Endocrinologists; ACE,American College of Endocrinology; ADA, American Diabetes Association; BP, blood pressure; CVD, cardiovascular disease; HDL-C, high-density lipoprotein-cholesterol; LDL-C, low-density lipoprotein-cholesterol. 
benefit. GLP-1 receptor agonists have the added benefit of promoting weight loss. ${ }^{8}$

The International Diabetes Center algorithm also includes goals and options for glycemic treatment. ${ }^{7}$ Beginning with complete lifestyle management, this algorithm recommends commencing treatment with MET and advancing to a twodrug therapy if target glycemic goals are not achieved within three months. The algorithm also includes guidance on the effect of antidiabetes therapy on hypoglycemia and weight (ie, among two drug therapies, only one promotes weight loss; the combination of MET and GLP-1 receptor agonist). ${ }^{7}$

A pathophysiology-based algorithm has been recently presented as an alternative to the ADA guidelines for the treatment of type 2 diabetes. $^{6}$ This algorithm is based on targeting the pathophysiologic defects associated with diabetes, including impaired insulin secretion, increased lipolysis, decreased glucose uptake, and increased hepatic glucose production. ${ }^{6}$ Through lifestyle changes and triple therapy with a TZD, MET, and the GLP-1 receptor agonist exenatide, the regimen durably lowers hyperglycemia without inducing weight gain. ${ }^{6}$ Early commencement with this antidiabetes regimen should help to delay/prevent the progressive $\beta$-cell failure experienced by patients with type 2 diabetes. ${ }^{6}$

\section{Newer therapies for type $\mathbf{2}$ diabetes Amylin agonist}

Patients with type 2 diabetes are deficient in the neuroendocrine hormone amylin, which is secreted by pancreatic $\beta$-cells (along with insulin) in response to nutrient intake. ${ }^{31}$ Amylin suppresses postprandial glucagon secretion and regulates gastric emptying and appetite. ${ }^{31}$ Treatment with pramlintide, a synthetic amylin agonist, as adjunctive therapy to insulin with or without oral antidiabetes agents, has been associated with improvements in glycemic control (up to $-0.7 \%$ reduction in $\mathrm{HbA}_{1 \mathrm{c}}$ ), weight (up to $-1.6 \mathrm{~kg}$ ), and selected markers of CV risk (postprandial excursions of glucose, nitrotyrosine, and oxidized low-density lipoprotein-cholesterol [LDL-C]), without increased risk of hypoglycemia in patients with type 2 diabetes. ${ }^{32-34}$

\section{GLP-I receptor agonists}

Incretins are gastrointestinal hormones that stimulate insulin release from pancreatic $\beta$-cells. The "incretin effect" describes the increased insulin secretion resulting from oral compared with intravenous glucose administration. ${ }^{35}$ It has been estimated that the incretin effect represents between $30 \%$ and $60 \%$ of the peripheral venous insulin response. ${ }^{35}$ As this represents a considerable proportion of postprandial insulin release, interest in developing incretins as diabetes treatment has increased over the past several years.

GLP-1 is a potent incretin hormone that is rapidly secreted by gut cells following a meal, ${ }^{36}$ although the enzyme DPP-IV rapidly metabolizes GLP-1 to an inactive fragment. ${ }^{37}$ Thus, the GLP-1 signaling pathway has been leveraged as a focus for diabetes research in two ways. First, GLP-1 receptor agonists have been developed that are resistant to DPP-IV

Table 3 Effects on $\mathrm{HbA}_{\mathrm{Ic}}$, advantages and disadvantages of oral and parenteral antidiabetes agents ${ }^{13}$

\begin{tabular}{lll}
\hline Intervention & Advantages & Disadvantages \\
\hline Sulfonylureas & Rapidly effective & $\begin{array}{l}\text { Weight gain, hypoglycemia (especially with glyburide } \\
\text { [dibenclamide in the EU] and chlorpropamide) }\end{array}$ \\
Metformin & Weight neutral & $\begin{array}{l}\text { Gl side effects, contraindicated in patients with renal } \\
\text { insufficiency }\end{array}$ \\
TZDs & Improved lipid profile (pioglitazone), & Weight gain, fluid retention, CHF, bone fractures, \\
& potential decrease in MI (pioglitazone) & expensive, potential increase in MI (rosiglitazone) \\
$\alpha$-Glucosidase inhibitors & Weight neutral & Frequent Gl side effects, TID dosing \\
Glinides (meglitinides) & Rapidly effective & Weight gain,TID dosing, hypoglycemia \\
DPP-IV inhibitors & Weight neutral & Risk of pancreatitis, renal failure \\
Insulin & No dose limit, rapidly effective, & Weight gain, multiple daily injections, monitoring, \\
& improved lipid profile & hypoglycemia \\
GLP-I receptor agonist & Weight loss & $\begin{array}{l}\text { Frequent Gl side effects, risk of pancreatitis, renal } \\
\text { failure }\end{array}$ \\
Amylin/amylin analogue & Weight loss & Frequent Gl side effects, TID dosing, long-term \\
(pramlintide) & safety not established
\end{tabular}

Abbreviations: $\mathrm{CHF}$, congestive heart failure; DPP-IV, dipeptidyl peptidase-IV; EU, European Union; GI, gastrointestinal; GLP-I, glucagon-like peptide-I; MI, myocardial infarction; TZDs, thiazolidinediones. 
Tier 1: Well-validated core therapies

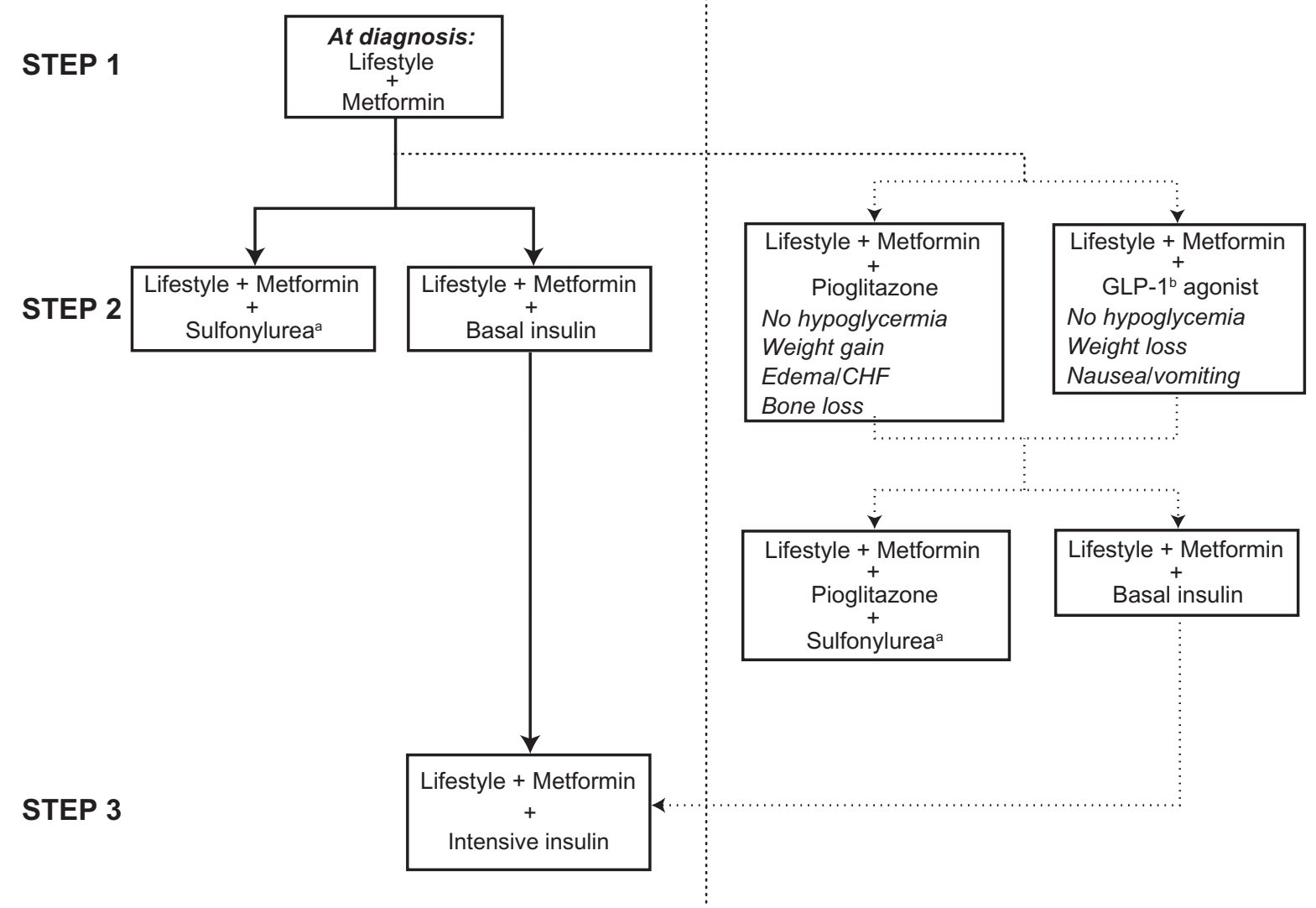

Figure I ADA/EASD consensus guidelines treatment algorithm for patients with type 2 diabetes. Reinforce lifestyle interventions at every visit; check $\mathrm{HbA}$ every three months until $\mathrm{HbA}_{\mathrm{Ic}}$ is $<7 \%$ and then at least every six months. The interventions should be changed if $\mathrm{HbA}_{\mathrm{Ic}}$ is $\geq 7 \%$. Copyright $\odot 2009$. Adapted with permission from Nathan DM, Buse JB, Davidson MB, et al. Medical management of hyperglycemia in type 2 diabetes: a consensus algorithm for the initiation and adjustment of therapy: a consensus statement of the American Diabetes Association and the European Association for the Study of Diabetes. Diabetes Care. 2009;32(I):193-203.

Notes: aSulfonylureas other than glyburide or chlorpropamide. Insufficient clinical use to be confident regarding safety.

Abbreviations: ADA, American Diabetes Association; CHF, congestive heart failure; EASD, European Association for the Study of Diabetes; GLP-I, glucagon-like peptide-I.

degradation, and second, small molecules that inhibit DPP-IV activity have been developed. ${ }^{37}$

Exenatide, the synthetic form of exendin-4, which is $53 \%$ homologous to human GLP-1, binds the GLP-1 receptor agonist on pancreatic $\beta$-cells to potentiate insulin secretion. ${ }^{8,38}$ Exenatide has been approved by the US Food and Drug Administration (FDA) for use as an adjunctive therapy to improve glycemic control in patients with type 2 diabetes. ${ }^{8}$ Exenatide was shown to improve glucose levels and a number of CVD risk factors, including body weight, triglycerides (TG), total cholesterol, HDL-C, LDL-C, systolic $\mathrm{BP}$ (SBP) and diastolic BP in patients with type 2 diabetes treated for $\geq 3$ years. ${ }^{39}$ In patients with type 2 diabetes previously treated with MET, the addition of exenatide improved hyperglycemic clamp-derived measures of $\beta$-cell function more than insulin glargine $(P<0.0001) .{ }^{40}$ In addition, in a retrospective database study, treatment with exenatide was associated with significant reduction in mean body weight $(-2.7 \mathrm{~kg} ; P<0.001)$, BMI $\left(-0.9 \mathrm{~kg} / \mathrm{m}^{2} ; P<0.001\right)$, abdominal girth $(-2.9 \mathrm{~cm} ; P<0.001)$, total cholesterol $(-7.4 \mathrm{mg} / \mathrm{dL} ; P<0.001)$, TG $(-16.7 \mathrm{mg} / \mathrm{dL} ; P<0.001)$, and $\mathrm{BP}(-2.6 /-1.2 \mathrm{~mm} \mathrm{Hg} ; P<0.03){ }^{41}$

In pooled datasets from two studies, the addition of exenatide to patients treated with MET and an SFU for six months resulted in more patients reaching an $\mathrm{HbA}_{1 \mathrm{c}} \leq 6.5 \%$ with significantly greater reductions in body weight (up to $-3.7 \mathrm{~kg} ; P<0.0001)$ and SBP $(-7.2 \mathrm{~mm} \mathrm{Hg} ; P<0.005)$ than in patients who received insulin glargine or biphasic insulin aspart. ${ }^{42}$ In two other studies, exenatide produced greater reductions in SBP than either biphasic insulin aspart $(-4.9 \mathrm{~mm} \mathrm{Hg}$ vs $-0.5 \mathrm{~mm} \mathrm{Hg} ; P<0.0001)$ or placebo $(-1.7 \mathrm{~mm} \mathrm{Hg}$ vs $+0.4 \mathrm{~mm} \mathrm{Hg} ; P<0.0005){ }^{43}$

A long-acting, once-weekly formulation of exenatide (which lowers glucose via the same mechanism as the 
approved BID formulation) is currently under regulatory review by the US FDA. ${ }^{36,44}$ A 30 -week, noninferiority trial in patients with type 2 diabetes receiving MET, a SFU, a TZD, or a combination of two of these agents, was conducted to compare exenatide administered twice daily to once weekly. ${ }^{44}$ Both treatment groups had reductions in $\mathrm{HbA}_{1 \mathrm{c}}$ by week 6 . Beginning at week 10 and continuing through the remainder of the trial, exenatide once weekly was associated with greater reductions in $\mathrm{HbA}_{1 \mathrm{c}}$ than twice-daily dosing. ${ }^{44}$ After 30 weeks, the mean $\mathrm{HbA}_{1 \mathrm{c}}$ reduction was $-1.9 \%$ for exenatide once weekly versus $-1.5 \%$ for twice daily $(P=0.002) .{ }^{44}$ Weight loss was similar $(-3.7 \mathrm{~kg})$ with both treatment regimens. ${ }^{44}$ Incidence of transient treatment-related nausea was significantly greater in the twice-daily group $(34 \%$; $50 / 145)$ compared with the once-weekly group $(26.4 \%$; 39/148; $P<0.05)$, while transient injection site pruritus was more commonly reported in the once-weekly group $(17.6 \%$; $26 / 148$ vs $1.4 \% ; 2 / 145)$. These events subsided over the duration of the study. ${ }^{44}$

Liraglutide, an injectable GLP-1 receptor agonist with 97\% homology to human GLP-1 and partial resistance to DPP-IV (through amino acid substitution and palmitate side chain addition), is being investigated in a once-daily formulation, and has recently been approved for use in the European Union. ${ }^{36}$ In the 26-week Liraglutide Effect and Action in Diabetes (LEAD)-2 MET study, patients with type 2 diabetes on a stable regimen of MET were treated with liraglutide, glimepiride, or placebo. ${ }^{45}$ After 12 weeks of therapy, liraglutide and glimepiride were associated with greater reductions in $\mathrm{HbA}_{1 \mathrm{c}}(-0.7 \%$ to $-1.0 \%)$ than placebo $(-0.09 \% ; P<0.0001) .{ }^{45}$ Liraglutide reduced body weight up to $-2.8 \mathrm{~kg}$ compared with a $+1 \mathrm{~kg}$ weight gain with glimepiride $(P<0.0001) .{ }^{45}$ Liraglutide was associated with a greater incidence of nausea, vomiting, and diarrhea than either glimepiride or placebo, although the events were transient and subsided over the course of the study. ${ }^{45}$

In a 52-week study, patients with type 2 diabetes receiving liraglutide monotherapy had significantly greater reductions from baseline $\mathrm{HbA}_{1 \mathrm{c}}(\sim 8.3 \%)$ than patients receiving glimepiride monotherapy $(-1.1 \%$ vs $-0.5 \% ; P<0.001) .{ }^{46}$ Unlike glimepiride, treatment with liraglutide was associated with weight loss (approximately $-2.3 \mathrm{~kg}$ ) while patients on glimepiride gained approximately $1 \mathrm{~kg}(P=0.0001) .{ }^{46}$

\section{DPP-IV inhibitors}

Sitagliptin, an oral antidiabetes agent, has been shown to inhibit plasma DPP-IV activity by $\sim 90 \%$ after two hours and by $\sim 80 \%$ after 24 hours post-dose. ${ }^{47}$ Sitagliptin monotherapy was associated with significant $(P<0.001)$ improvement in $\mathrm{HbA}_{1 \mathrm{c}}$ (up to $-0.9 \%$ ) in a 24-week study of patients with a mean 4.4-year duration of type 2 diabetes. ${ }^{48}$

Sitagliptin has also been studied in type 2 diabetes patients with inadequate glycemic control on MET alone. ${ }^{49}$ After 26 weeks of therapy, sitagliptin was well tolerated and provided significant improvement in $\mathrm{HbA}_{1 \mathrm{c}}$ compared with placebo $(-0.7 \%$ vs $-0.02 \% ; P<0.001) .{ }^{49}$ In patients receiving inadequate glycemic control on pioglitazone, sitagliptin provided significant decreases $(-0.9 \%)$ from baseline $\mathrm{HbA}_{1 \mathrm{c}}(\sim 8.1 \%)$ compared with placebo $(-0.2 \%$; $P<0.001) .^{50}$

Saxagliptin, another DPP-IV inhibitor, was recently approved for use in type 2 diabetes by the US FDA. In clinical studies, saxagliptin has been demonstrated to be effective in glucose-lowering in patients with type 2 diabetes either as monotherapy ${ }^{51}$ or in combination with other agents (eg, MET, SFU). ${ }^{52,53}$

\section{Implications of treatment decisions on the reduction of CVD risk}

Based on data from multiple clinical trials, the current $\mathrm{HbA}_{1 \mathrm{c}}$ goals for patients with type 2 diabetes appear appropriate. However, $\mathrm{HbA}_{1 \mathrm{c}}$ values lower than $6.5 \%$ to $7 \%$ may not provide any clinical advantages in certain patient populations and may, in fact, increase mortality in patients with an already elevated risk for CVD. Although weight loss may be difficult for some patients with type 2 diabetes to achieve, it is associated with improvements in CVD- and diabetesrelated risks. ${ }^{21}$ Additionally, longer duration of type 2 diabetes is associated with poorer clinical outcomes. ${ }^{9,13}$ Because patients with type 2 diabetes commonly present with varying levels of these risks, it is important to customize antidiabetes treatments within the framework of recommended treatment guidelines. Evidence continues to accumulate in support of newer antidiabetes agents, such as incretin-based therapies (GLP-1 receptor agonists and DPP-IV inhibitors), which improve hyperglycemia and other CVD risk factors/markers (eg, weight, BP, lipids). These incretin-based therapies address an additional hormone deficiency present in patients with type 2 diabetes and expand the options for optimizing glucose control and management of the disease. However, undue delay in initiating insulin therapy with deteriorating glycemic control in order to try a variety of new noninsulin therapies should be avoided. Earlier initiation of insulin treatment should be considered to correct rising glycemia, particularly in patients with type 2 diabetes of more than 10 years duration. 


\section{Conclusions}

Patients with type 2 diabetes have an elevated risk of CVD secondary to their hyperglycemia. This risk is compounded by the presence of common comorbidities including overweight/ obesity, hypertension, and dyslipidemia. Addressing these risks simultaneously has beneficial effects on treatment outcomes. Some of the current antidiabetes pharmacotherapies, such as MET, $\alpha$-glucosidase inhibitors, and incretin-based therapies have beneficial effects on hyperglycemia and other surrogate markers of CVD risk without increasing weight. SFUs, TZDs, glinides, and insulin control glycemia and reduce $\mathrm{CV}$ risk factors but are associated with weight gain.

The duration of diabetes has an independent and negative impact on CVD risk and is related to the progression of morbidity and mortality. As evidenced by the results from recent, large-scale clinical trials, $\mathrm{HbA}_{1 \mathrm{c}}$ target goals do not need to be drastically revised for patients with type 2 diabetes. Prompt initiation of antidiabetes treatment and individualized clinical judgment for each patient is paramount in treating hyperglycemia and its comorbidities. Earlier initiation of insulin therapy to optimize glycemic control should be considered in the management of type 2 diabetes.

\section{Disclosures}

Pasquale J Palumbo has no disclosures or conflicts. Jonathan M Wert has served as a consultant for educational services for Amylin Pharmaceuticals, Inc. and Eli Lilly and Company.

\section{References}

1. Centers for Disease Control and Prevention. 2007 National Diabetes Fact Sheet. July 23, 2008. Available at http://www.cdc.gov/diabetes/ pubs/estimates07.htm. Accessed September 10, 2009.

2. American Diabetes Association. Standards of medical care in diabetes - 2009. Diabetes Care. 2009;32 Suppl 1:S13-S61.

3. Lloyd-Jones D, Adams R, Carnethon M, et al. Heart disease and stroke statistics - 2009 update: a report from the American Heart Association Statistics Committee and Stroke Statistics Subcommittee. Circulation 2009;119(3):480-486.

4. Eeg-Olofsson K, Cederholm J, Nilsson PM, et al. Risk of cardiovascular disease and mortality in overweight and obese patients with type 2 diabetes: an observational study in 13,087 patients. Diabetologia. 2009;52(1):65-73.

5. Rodbard HW, Blonde L, Braithwaite SS, et al. American Association of Clinical Endocrinologists medical guidelines for clinical practice for the management of diabetes mellitus. Endocr Pract. 2007;13 Suppl 1:1-68.

6. DeFronzo RA. Banting Lecture. From the triumvirate to the ominous octet: a new paradigm for the treatment of type 2 diabetes mellitus. Diabetes. 2009;58(4):773-795.

7. International Diabetes Center. Treatment algorithm for glucose control in type 2 diabetes: IDC treatment of type 2 diabetes: Glycemic control. Available at http://www.parknicollet.com/diabetes/profServices/ algorithm.cfm. Accessed September 10, 2009.

8. Nathan DM, Buse JB, Davidson MB, et al. Medical management of hyperglycemia in type 2 diabetes: a consensus algorithm for the initiation and adjustment of therapy: a consensus statement of the American Diabetes Association and the European Association for the Study of Diabetes. Diabetes Care. 2009;32(1):193-203.
9. Gerstein HC, Miller ME, Byington RP, et al; for the Action to Control Cardiovascular Risk in Diabetes (ACCORD) Study Group. Effects of intensive glucose lowering in type 2 diabetes. $N$ Engl $\mathrm{J} \mathrm{Med}$. 2008;358(24):2545-2559.

10. Patel A, MacMahon S, Chalmers J, et al; for the Action in Diabetes and Vascular Disease: Preterax and Diamicron Modified Release and Controlled Evaluation (ADVANCE) Collaborative Group. Intensive blood glucose control and vascular outcomes in patients with type 2 diabetes. N Engl J Med. 2008;358(24):2560-2572.

11. Duckworth W, Abraira C, Moritz T, et al. Glucose control and vascular complications in veterans with type 2 diabetes. $N$ Engl J Med. 2009; 360(2):129-139.

12. Gaede P, Lund-Andersen H, Parving HH, Pedersen O. Effect of a multifactorial intervention on mortality in type 2 diabetes. $N$ Engl J Med 2008;358(6):580-591.

13. Skyler JS, Bergenstal R, Bonow RO, et al. Intensive glycemic control and the prevention of cardiovascular events: implications of the ACCORD, ADVANCE, and VA diabetes trials: a position statement of the American Diabetes Association and a scientific statement of the American College of Cardiology Foundation and the American Heart Association. Diabetes Care. 2009;32(1) 187-192.

14. Skyler JS. Diabetic complications. The importance of glucose control. Endocrinol Metab Clin North Am. 1996;25(2):243-254.

15. Nathan DM, Cleary PA, Backlund JY, et al; for the Diabetes Control and Complications Trial/Epidemiology of Diabetes Interventions and Complications (DCCT/EDIC) Study Research Group. Intensive diabetes treatment and cardiovascular disease in patients with type 1 diabetes. N Eng J Med. 2005;353(25):2643-2653.

16. Klein R, Knudtson MD, Lee KE, Gangnon R, Klein BE. The Wisconsin Epidemiologic Study of Diabetic Retinopathy XXIII: the twenty-fiveyear incidence of macular edema in persons with type 1 diabetes. Ophthalmology. 2009;116(3):497-503.

17. Hirai FE, Knudtson MD, Klein BE, Klein R. Clinically significant macular edema and survival in type 1 and type 2 diabetes. Am J Ophthalmol. 2008;145(4):700-706.

18. Klein R, Klein BE, Moss SE, Wong TY. Retinal vessel caliber and microvascular and macrovascular disease in type 2 diabetes: XXI: the Wisconsin Epidemiologic Study of Diabetic Retinopathy. Ophthalmology. 2007;114(10):1884-1892.

19. Holman RR, Paul SK, Bethel MA, Matthews DR, Neil HA. 10-year follow-up of intensive glucose control in type 2 diabetes. $N$ Engl J Med. 2008;359(15):1577-1589.

20. Holman RR, Paul SK, Bethel MA, Neil HA, Matthews DR. Long-term follow-up after tight control of blood pressure in type 2 diabetes. $N E n g l$ J Med. 2008;359(15):1565-1576.

21. Pi-Sunyer X, Blackburn G, Brancati FL, et al. Reduction in weight and cardiovascular disease risk factors in individuals with type 2 diabetes: one-year results of the look AHEAD trial. Diabetes Care 2007;30(6):1374-1383.

22. Fox CS, Pencina MJ, Wilson PW, Paynter NP, Vasan RS, D’Agostino RB Sr. Lifetime risk of cardiovascular disease among individuals with and without diabetes stratified by obesity status in the Framingham heart study. Diabetes Care. 2008;31(8): $1582-1584$

23. Malmberg K. Role of insulin-glucose infusion in outcomes after acute myocardial infarction: the diabetes and insulin-glucose infusion in acute myocardial infarction (DIGAMI) study. Endocr Pract. 2004;10 Suppl 2: 13-16.

24. Mellbin LG, Malmberg K, Norhammar A, Wedel H, Ryden L. The impact of glucose lowering treatment on long-term prognosis in patients with type 2 diabetes and myocardial infarction: a report from the DIGAMI 2 trial. Eur Heart J. 2008;29(2):166-176.

25. Mellbin LG, Malmberg K, Waldenstrom A, Wedel H, Ryden L. Prognostic implications of hypoglycaemic episodes during hospitalisation for myocardial infarction in patients with type 2 diabetes: a report from the DIGAMI 2 trial. Heart. 2009;95(9):721-727. 
26. Aas AM, Ohrvik J, Malmberg K, Ryden L, Birkeland KI. Insulin-induced weight gain and cardiovascular events in patients with type 2 diabetes. A report from the DIGAMI 2 study. Diabetes Obes Metab. 2009;11(4):323-329.

27. BARI 2D Study Group. Baseline characteristics of patients with diabetes and coronary artery disease enrolled in the Bypass Angioplasty Revascularization Investigation 2 Diabetes (BARI 2D) trial. Am Heart J. 2008;156(3):528-536.

28. Frye RL, August P, Brooks MM, et al; BARI 2D Study Group. A randomized trial of therapies for type 2 diabetes and coronary artery disease. N Engl J Med. 2009;360(24):2503-2515.

29. Purnell JQ, Weyer C. Weight effect of current and experimental drugs for diabetes mellitus: from promotion to alleviation of obesity. Treat Endocrinol. 2003;2(1):33-47.

30. Henry RR. Evolving concepts of type 2 diabetes management with oral medications: new approaches to an old disease. Curr Med Res Opin. 2008;24(8):2189-2202.

31. Edelman SV. Optimizing diabetes treatment using an amylin analogue. Diabetes Educ. 2008;34 Suppl 1:4S-10S.

32. Hollander PA, Levy P, Fineman MS, et al. Pramlintide as an adjunct to insulin therapy improves long-term glycemic and weight control in patients with type 2 diabetes: a 1-year randomized controlled trial. Diabetes Care. 2003;26(3):784-790.

33. Hoogwerf BJ, Doshi KB, Diab D. Pramlintide, the synthetic analogue of amylin: physiology, pathophysiology, and effects on glycemic control, body weight, and selected biomarkers of vascular risk. Vasc Health Risk Manag. 2008;4(2):355-362.

34. Riddle M, Frias J, Zhang B, et al. Pramlintide improved glycemic control and reduced weight in patients with type 2 diabetes using basal insulin. Diabetes Care. 2007;30(11):2794-2799.

35. Nauck MA, Homberger E, Siegel EG, et al. Incretin effects of increasing glucose loads in man calculated from venous insulin and C-peptide responses. J Clin Endocrinol Metab. 1986;63(2):492-498.

36. Drucker DJ, Nauck MA. The incretin system: glucagon-like peptide-1 receptor agonists and dipeptidyl peptidase- 4 inhibitors in type 2 diabetes. Lancet. 2006;368(9548):1696-1705.

37. Deacon CF, Nauck MA, Toft-Nielsen M, Pridal L, Willms B, Holst JJ. Both subcutaneously and intravenously administered glucagon-like peptide I are rapidly degraded from the NH2-terminus in type II diabetic patients and in healthy subjects. Diabetes. 1995;44(9): $1126-1131$.

38. Eng J, Kleinman WA, Singh L, Singh G, Raufman JP. Isolation and characterization of exendin-4, an exendin-3 analogue, from Heloderma suspectum venom. Further evidence for an exendin receptor on dispersed acini from guinea pig pancreas. $J$ Biol Chem. 1992;267(11):7402-7405.

39. Klonoff DC, Buse JB, Nielsen LL, et al. Exenatide effects on diabetes, obesity, cardiovascular risk factors and hepatic biomarkers in patients with type 2 diabetes treated for at least 3 years. Curr Med Res Opin. 2008;24(1):275-286.

40. Bunck MC, Diamant M, Corner A, et al. One-year treatment with exenatide improves beta-cell function, compared with insulin glargine, in metformin-treated type 2 diabetic patients: a randomized, controlled trial. Diabetes Care. 2009;32(5):762-768.

41. Bhushan R, Elkind-Hirsch KE, Bhushan M, Butler WJ, Duncan K, Marrioneaux O. Exenatide use in the management of metabolic syndrome: a retrospective database study. Endocr Pract. 2008;14(8):993-999.
42. Maggs D, Bhole D, Yan P, Stonehouse A, Brodows R, Okerson T. Exenatide is superior to insulin in attaining tight glycaemic control $(\mathrm{A} 1 \mathrm{C} \leq 6.5 \%)$ with a more favorable accompanying metabolic profile. Presented at the 44th Annual Meeting of the European Association for the Study of Diabetes; September 7-11, 2008; Rome, Italy. Abstract 876

43. Okerson T, Yan P, Stonehouse A, Brodows R, Bhole D. Exenatide improved systolic blood pressure compared to insulin or placebo in patients with type 2 diabetes. Presented at the 44th Annual Meeting of the European Association for the Study of Diabetes; September 7-11, 2008; Rome, Italy. Abstract 877.

44. Drucker DJ, Buse JB, Taylor K, et al. Exenatide once weekly versus twice daily for the treatment of type 2 diabetes: a randomised, openlabel, non-inferiority study. Lancet. 2008;372(9645):1240-1250.

45. Nauck M, Frid A, Hermansen K, et al. Efficacy and safety comparison of liraglutide, glimepiride, and placebo, all in combination with metformin, in type 2 diabetes: the LEAD (liraglutide effect and action in diabetes)-2 study. Diabetes Care. 2009;32(1):84-90.

46. Garber A, Henry R, Ratner R, et al. Liraglutide versus glimepiride monotherapy for type 2 diabetes (LEAD-3 Mono): a randomised, 52-week, phase III, double-blind, parallel-treatment trial. Lancet. 2009;373(9662):473-481

47. Herman GA, Bergman A, Stevens C, et al. Effect of single oral doses of sitagliptin, a dipeptidyl peptidase- 4 inhibitor, on incretin and plasma glucose levels after an oral glucose tolerance test in patients with type 2 diabetes. J Clin Endocrinol Metab. 2006;91(11):4612-4619.

48. Aschner P, Kipnes MS, Lunceford JK, Sanchez M, Mickel C, WilliamsHerman DE. Effect of the dipeptidyl peptidase-4 inhibitor sitagliptin as monotherapy on glycemic control in patients with type 2 diabetes. Diabetes Care. 2006;29(12):2632-2637.

49. Charbonnel B, Karasik A, Liu J, Wu M, Meininger G. Efficacy and safety of the dipeptidyl peptidase- 4 inhibitor sitagliptin added to ongoing metformin therapy in patients with type 2 diabetes inadequately controlled with metformin alone. Diabetes Care. 2006;29(12):2638-2643.

50. Rosenstock J, Brazg R, Andryuk PJ, Lu K, Stein P. Efficacy and safety of the dipeptidyl peptidase-4 inhibitor sitagliptin added to ongoing pioglitazone therapy in patients with type 2 diabetes: a 24-week, multicenter, randomized, double-blind, placebo-controlled, parallel-group study. Clin Ther. 2006;28(10):1556-1568.

51. Rosenstock J, Aguilar-Salinas C, Klein E, Nepal S, List J, Chen R; for the CV181-011 Study Investigators. Effect of saxagliptin monotherapy in treatment-naïve patients with type 2 diabetes. Curr Med Res Opin. 2009;25(10):2401-2411.

52. Chacra A, Tan G, Apanovitch A, Ravichandran S, List J, Chen R. Saxagliptin added to a submaximal dose of sulphonylurea improves glycaemic control compared with uptitration of sulphonylurea in patients with type 2 diabetes: a randomized controlled trial. Int J Clin Pract. 2009;63(9):1395-1406.

53. Jadzinsky M, Pfutzner A, Paz-Pacheco E, Xu Z, Allen E, Chen R; for the CV181-039 Investigators. Saxagliptin given in combination with metformin as initial therapy improves glycemic control in patients with type 2 diabetes compared with either monotherapy: a randomized controlled trial. Diab Obese Metab. 2009;(6):611-622.
Vascular Health and Risk Management

\section{Publish your work in this journal}

Vascular Health and Risk Management is an international, peerreviewed journal of therapeutics and risk management, focusing on concise rapid reporting of clinical studies on the processes involved in the maintenance of vascular health; the monitoring, prevention and treatment of vascular disease and its sequelae; and the involvement of

\section{Dovepress}

metabolic disorders, particularly diabetes. This journal is indexed on PubMed Central and MedLine. The manuscript management system is completely online and includes a very quick and fair peer-review system, which is all easy to use. Visit http://www.dovepress.com/ testimonials.php to read real quotes from published authors. 